This is an Accepted Manuscript of a book chapter published by Routledge in Resisting biopolitics : philosophical, political and performative strategies on 06/10/2015, available online: https://www.routledge.com/Resisting-Biopolitics-Philosophical-Political-andPerformative-Strategies/Wilmer-Zukauskaite/p/book/9781138789487 


\section{Digital Biopolitics: The Image of Life}

\section{F. J. Colman}

The human body has always been a political site. Its biological, ontological, and material constitution, given and directed by its geo-cultural situation, means that its genetic materiality and thus its outward appearance will affect its position and its access to other constituted political fields. In this chapter, I refer to this imaged body as a living capital body (lcb), as an object ontologically formed and durationally determined within contemporary late capitalist cultures. In its relational constitution, the lcb comes to be visible, and able to be visualized, through certain political frames, such as the politics of the racialized skin, the politics of the gender, the politics of the age, the politics of the place of birth, and so on. From Marx, we understand that the actions of the value of the body of the worker is the living value the proletariat's body. This value situates that body within its industrial political field of work (for example, see Lefebvre 2009, 146ff). In contemporary terms, the gender and racialized configurations of the value accorded to the living labor of the worker's body, within a digitally constituted political field of work, mean that the lcb is a coded, encrypted image, and exists within a digital data field, where all movements are monitored, but outcomes are nevertheless inchoate due to the nature of data. The lcb is held and holds a force of variable strength, feeding and animating the system of capital, but in ways different to the industrial lcb. Post-Foucault, the technology-image produced by the biopoliticized, digitized body is creating new political fields, recognizable by their aesthetic domains. 
The chapter addresses ten different points, describing where and how the visible identification of the body, as an lcb affects and contributes to the ontological production of life. Focussing on the digital ontology of the body, the chapter begins by examining the body reformed as an informatics image in bio-identity cards, which enable a tight control of any migratory movements of lcbs across different nation states, and regulate the lcb's access to different political territories. The chapter asks what constitutes a digital biopolitics, examining how the lcb is measured and valued is addressed, in relation to technological visualization of the body as $1 \mathrm{cb}$, and the control, manipulation and experimentation on and of its properties. The chapter concludes with speculation on the body as a mattered image of digital code.

1. Your body is an informatics image: As a resident in the territory, but not a citizen, the living capital body (the lcb) has its (non-territorial) biodata on digital store for regular testing of its identity through a range of biometric measures. In attending to the processes of identification, when the lcb is entering or exiting non-home territories, alongside other non-citizens, usually at governmentally administered or sub-contracted checkpoints and centers, there is never any room for speculation upon the ethics, politics, economics, tragedies, or ironies of the situation of the collective and individuated bodies being identified, recoded, and classified, according to the laws of the place and time, the political situation of the checkpoint, and the psychological condition of the border-pass worker. There is no space or opportunity given to address the biopolitical situation the body is being forced into, by the sheer randomness of it being born over there, and not 
here. The lcb holds a temporary hall pass, and must queue in the line. The walls are decorated with illegal immigration warnings, notifications of infectious disease protocols, and police requests for information related to events deemed illegal by the contemporary law. Other lcbs visibly identifiable and coded as politically different to the mandates of residency requirements join the long queues. These lcbs are in the wrong place and the wrong time, or born on a piece of land that others desire, and are thus rendered as illegal, dangerous, threatening, or simply expendable. At the last re-entry into the territories the lcb was asked in a sarcastic and hostile tone in reference to the temporary resident card: ${ }^{1}$ and how did you get this? Individual fingers, up to ten, are scanned to match the lcb's fingerprints with the coded biocard, and the lcb's face studied for a visual match with the poorly reproduced image of the lcb's face on the card. An iris scan of the lcb is called for to ensure further matching of identification measurements. At other checkpoints, the lcb's iris scan is printed out as a bar code that has a temporal expiry time, superceeding the coded-card, activated so that the lcb must move from one entry/exit point to another within a specified duration. At each gateway, the data code of the iris of the lcb is scanned and matched against the data held, to ensure that it is the correct lcb. Measured thus, they may or may not pass and proceed. At the last re-entry into the territories the lcb noticed that many other lcbs were refused entry and were led away to opaque glass-clad rooms, rendering them invisible. The lcbs that belong to the territory are also herded through checkpoints, with qualititative questions sometimes asked to measure and record the movement and activity of their lcb: holiday or work? Each movement of the lcbs is recorded, accorded a value, each change of position of the lcbs is counted, digitally 
stored, contribution to the system formulated. Each lcb is carded, biocoded. For some this is a possible future, for others it is already a fact.

2. Exits and entrances are determined by the biocoded body. Territories are determined by specific epistemic images of life and their economic control is the work of

governments. By the bloody-mindedness of decisions made by the governemental / police / management to organize the facilitation of bodies through checkpoints, through artificial borders, each body that arrives from "not here" is treated as a suspicious, outside body, through this (and many other such) processes of bio/racialized/gendered exclusion, ethnic identification, mockery through stereotyping, insufficient support mechanisms for addressing the psychological and physical stresses of othering, and exclusion based on the territory of birth, and that territory's subsequent materialization of a political body. The image of life described here is the biocoded body. The code includes its processing modes - sensory (auditory, rhythmic, intuitive, propreperceptual, haptic), cognitive, cultural - which are subject to cultural perceptual speeds (of attention, memory, utility), within the territory in which it lives. This lived body is an image field of digitized biopolitics and is comprised of a number of vectorial points: 1. it exists as a discrete "image" in the sense of the encoded visual data; 2. as an "imaged" representation of the matter of the lcb; 3 . as mediated through visualizing and encoding technologies that quantify the demographics of the living data; and 4. as the political imaginary of a resource as territory - which has a finite access, determined by privilege, chance, opportunity and creativity. 
3. The production of the lcb is the process of a biopolitics at work; where the matter of the bios is not that my mother was a computer (Hayles 2005), but that the lcb's biopolitical being is a ready-coded image of its life; that is its coded (genetic + birth country) informatics. This informatics is a biopolitical practice, a culture where the body matter, imaged, is not so much performed, as "materialized as information" (Haraway 1997, 134). The lcb is an individuated, coded card. A political tool. A subject. A piece of corporeal informatics represented by polymer, embedded with coded data of iris patterns, fingerprints, and photographs. The coded informatics of the identification card, or passport, is a filter portal enabling the claim of "biolegitimacy" (Fassin 2005), where the government only enables the lcb as a fostered subject if its chromosomic material matches the prescreened account of the lcb's recorded life situation, and determined social value. Biopolitical legitimation and classification by a sovereign power produces a biocode that facilitates a body's potential for capital production. Once allowed entry into the territory, the biocoded body's communal "inscription", as defines the modern biopolitical era, facilitates state power (Agamben 1998, 121). The biocoded lcb is enabled for economic actions of work, consumption, reproduction, service, death, recycling, and it is thus available, for "bio-experimentation" (Virilio 2000, 31). The selection of lcbs available for experimentation, as human history tells us, has been based on the bio-identification of particular kinds of lcbs, with various consequences (cf. Fan 1997, 6; Haraway 1997, 23ff; Agamben 1998, 166; Goodman, McElligott and Marks 2003). The lcb is the materially specific object that capitalism requires, and must be shaped as a desiring, obedient worker, willing to transform the potential power of its lcb into the production of other material objects for the capitalist system. This is an active 
conception of life; where the matter of the lcb is accorded value and activated as per its use value.

4. The bios is a dependent variable of laws that govern the lcb: As a fostered subject, the bios is a measurable account of a body in a specific territory (the independent variable) at a specific time. But this bios is constructed through a complex ecology; as it is hosted by its historical technological mediation, and contingent upon the geographically determining precarity of the genetic and culturally made body, it is not always completely containable. Technologies enable mutation of the controlled identification. Even though the bios can change through hormones, enzymes, cultural and political factors, it remains an administrable index of life, politicized and privatized. Harnessed into continual political utility, some lcbs can sell or trade, or be traded; sell a kidney, harvest and sell reproductive cells (eggs, sperm); harvest organs; harvest the blood, skin, bone; donate a child's placenta and birth cord; hire out a womb; and donate various parts or all of the lcb to science upon cessation of life. Other coded cards describe the process. To this extent, the lcb is in "possession", or partial "ownership" of its body, although its use value, coded as an lcb remains contingent upon its visual presentation within any given territory and marketplace in the world. Not all territories afford the same "privilege" of ownership of the lcb. Identified at junctures when human actions affect a change in the ways in which the matter of the world is configured, a bios is thus always a political measure, a political image of life. Given this measurable bios through its variables, to what extent does the imaged mediation of the bios contribute to the ontological production of life? 
5. Imaging structures of the matter of life have always been in use as cultural and political passkeys. The images of ancestors and of contemporaries, and of imagined futures fascinate with their depictions of strange and unknown, particular biopolitical systems. Every image provides very specific perceptual modeling tools with which the material realty of the world it depicts, frames, or evokes, is organized and created. Prehistoric drawings of alien figures and carvings of extinct animals existing in different territories depict particular biopolitical systems, Hollywood films another, and the macroscopy of nanoparticles of the cellular structures of things in the universe encode further images of life. As iconic as the Lascaux prehistoric code, is the visualized structure of the molecule chain as a spiralling ladder with double helix fibres. Scientists Francis Crick and James D. Watson proposed in 1953 that the doubled structure of deoxyribonucleic acid (DNA) molecules contain the genetic information of life. This analog lcb's DNA was first visualized through the technology of X-ray crystallography, which showed the molecular structure through the diffraction patterns made by the X-ray processes of the 1950s, and the double helix strands of DNA were illustrated with a hand drawing by Odile Crick (reproduced in Watson and Crick 1953). However the early diffractive images did not enable the structural code to be cracked, as it was assumed that the acid fibres would act and look like other crystalline chemical structures (Lydon 2003, 4). Later on in that century, the technology of atomic force microscopy enabled the nanoscopic visualization of DNA (Leung, et al. 2012), and since then, further perception and comprehension of the DNA molecular chain matter has been facilitated through its visual mapping. The complexities of proteins, enzymes and chromosomic containers are organized by the taxonomy of the Human Genome Project into further ways of imagining 
the matter of life. As imaged matter, these forms have engendered new medical practices, so that trepanning the skull for a headache, or to let out a bad spirit contained in the body of Lascaux man, now has been displaced by the visualization of the brain that keyhole nanoscopic surgery allows.

6. Access to each of these imaged systems is the politics of the bios. The anthropos, animals, and supportive technologies of images of lcb communities [insert your lcb image here: the Lacaux caves / the victims of activities of militarization / the family holiday] can be visually recognized and described as mattered images. These images depict rituals of consumer practices, whose very matter of historical energy sources - light, coal, gas, bones, fat, and blood - bind together the technological filters at work to produce very specific images of life. The biopolitics of life is not to be understood as a passive or purely intentional lcb, an empty vessel waiting to be filled (the inner life), or a desire pursued and fulfilled by exterior matters. The question of biopolitical perceptual reality, and its predicated normativity, is one of the notions with which critics of the concept of the biopolitical engage. Taking Foucault's account of the discourses of power of the body to task, for example, Karan Barad argues that the idea of power cannot be limited to a discursive materiality of the body - the body is not simply an image of "something". Rather, the "constitution" of the body, through its materiality, "plays an active role in the workings of power" (Barad 2003, 809). When it comes to consumptive practices, however, the activity of the lcb, is not in "free" play, but in its material constitution; it is the result of a set of complex relational elements in process, which collectively combine and constitute how an lcb comes to be constituted by its 
access to energy forms, education, privilege, etc. - giving the lcb its image and thus its political situation.

\section{[INSERT FIGURE X.2 HERE]}

Figure 2: M. Osmond Wellcome Images. Cell after injecting DNA (a fertilized mouse oocyte having human DNA microinjected into one of its pronuclei).

7. The image of life becomes a digital biopolitics with the advent of digital technology, and as Donna Haraway points out, the lcb switched from being an analog proletariat worker to a cyborg / potential goddess in the 1980s (Haraway 1991). The lcb of the digital era is imaged in further terms (precariat, migrant, colored, gendered, criminalized), and although coded as data informatics, matched through an epistemic framing of DNA (suitable, potential, criminal, queer, etc.), the visualization of the lcb remains a primary originary site for registration of the politics of difference, and for ritual, political and cultural practices of classification. DNA cluster together, activate each other, and create new things. The image holds and is generative of primary epistemological "truth" sites for gender and racialized production - in themselves gendered and racist. In the age of digital reproducibility, the image plane of predicated lcbs is used as a measurement of all kinds of value systems. A digital biopolitics has provided a material agency for human life, producing a living image of cellular fields. Images generate creative singularities that are recognized as evidence of life, yet are also very much bound to their durationally situated technologies of production, where meanings and political perspectives are given by systems and structures in place. The lived holds a force of variable strength, energizing and animating the systems. Along 
with discoveries of the ability of DNA's capacity to store biological information, within the digital era's visualization processes, the image of life suddenly dilated again, a catalytic moment of when bio-speculation facilitated by technology opens "knowledge" into something new. With new digital technologies, medical practitioners are the new avant-garde, creating, manipulating, filtering, color saturating, cropping, collaging cells and images of all elements of the nanoscale matter of human, plant and mineral bodies cellular, molecular, nervous, vascular, organ systems (see the Wellcome Trust image library). These micro-mattered images of the human body make visible its structures, acids, and above all this body's dynamic finite coding. Like the bodies of the bison, bulls, and horses on the walls of Lascaux, this imaged matter of the complexities of human body proteins, enzymes and chromosomes is active. We have images of the lcb's egg harvesting, we recognize cell splicing, we know about the movements of biological sexed zygotes and their movements of propulsion and expulsion caused by hormones and enzymes. All kinds of internal matters of the body are given visual (although not audio) form. Such intensive imaging presents legal, educational, medical, and media makers with new kinds of problems associated with the diagrammatization and imaging of recording, examining, and manipulating the processes of the body. The creative singularity of Odile Crick produced a negentropic image of life. Her form arranged the informatics of life, and the elements of data can be harvested as biopolitical images codes for certain body types, with genetic traits, pre-cultural biological forms, which are then subject to political modeling contingent upon the socio-political ecology in which they are cultured. Media scientists produce images which are taken as predictive data of the future, where the politics of race are materialized through forms reminiscent of the 
methodologies of early anthropologists. ${ }^{2}$ But through the digital field, what does it mean for the political subject to be able to recognize images of herself as DNA strands, as cells in a petri dish; as a harvested and frozen egg; as a biometrically coded chip; when combined with other cellular organisms? The lcb has to be measured for the system to be sustained, contributing to an inordinate amount of expenditure on what might constitute the $1 \mathrm{cb}$ and its reality, its being, and any chance of harnessing the potential capital powers contained in its excesses - an afterlife? The scope of measurement is found cataloged in digitized images of religious orders and scientific data banks, in science museums that hold the relics of body parts, and in curious projects of medical databanks like the Visible Human Project, which contains images of thousands of planar slices of a male and female body, initially made into analog films, now digitized, taking a tour of the contours of the lcb (see Cartright 1997; US National Library of Medicine 2014). The provocations, which the images of the biodata of the lcb produce, engender the sense of a burgeoning technological frontier, where the search for the God Particle and the frequent discovery of new forms of enzymes and genetic modeling remind us of how 4,000 years of western medical discovery is still wanting. Humans submit to a dysfunctional system of their creation, and the divisions between them continue to grow.

8. Body, mattered image. If we have a culture where biopolitics is based upon a visual identification of bodies - the core of the contemporary politics of territory, gender and race - then, in addition to recognizing and deconstructing the ethics of this visual recognition, what are the aesthetic domains created by such imaging? The aesthetics of mediating bioimaging only have a partial grammar articulating their genealogies, 
disciplinary crossovers, potential formations, and material (the lived experience of their lcb). Digital lexicons are still being coded. We have the essential technological terms that describe what digital environments can enable, such as "hypertext" and "algorithm". We have the neologisms and core order words of the twentieth century's cognisance of the change from switch to code in the terms of medium, cyborg, digital prostheses, and the breadth of posthuman positions (cf. Braidotti 2007; 2013; Haraway 1991; Hayles 1999; MacCormack 2012) and those addressing the posthuman of the Anthropocene (Colebrook 2014). In each of these, the human body's anthropocentrism is savagely critiqued, dismembered. What is human life among other forms is one of the questions, but critically these positions also work toward dismantling the language of the human image, for example as Haraway notes: "Science projects are civics projects; they remake citizens" (Haraway 1997, 175). In terms of the narratives of material agency as potentially unethical creationist practices or the "thought experiment of extinction" (Colebrook 2014, np), what is presented by such technology images, of the intensive details of life as pre-bodied, or post-politically measured unembodied codes? In other words, what are the material components of such biopolitical images' negentropic mattered states? Comparison of a range of images shows various technologies acting as the durational platform for the lcb, while the biopolitics of the image affect a filter and activate a catalyst of information pertaining to the particular image. All images are durational, epistemological data (even the non-image of sound). In terms of intensity, their reach for presenting data (sensory, cognitive, cultural), is politically as well as chaotically directed, creative of an assemblage of meanings. Every image provides very specific perceptual modeling tools with which to organize and create the material reality 
of the world they depict, frame, or evoke (whether documentary vernacular, aesthetic surrealist, affective, propagandist, critical, etc.). For a perceptual methodology of the biopolitical image to be of interest, it must take into consideration the technological platform of its production and viewing, as well as the products that it has determined. Here the question of biopolitical perceptual reality and of normativity is one of the notions that further image analysis can address - working through the methodological platforms being used, but also always being critical of a textual reading of image as causal event. Image analysis currently situates the biopolitics of the body of organisms that we classify as animal, plant, human, as symbiotically dependent on other living features of the Earth required for life.

9. The visible human. How your body signifies visually and materially determines where it is allowed to exist, and what functions and freedoms it might have. The compression of the lcb into a completely commodifiable code, collectible, recyclable, or worthless swap card is not a new notion. But what is the image of the human? Is individuated experience a complete imaginary? This is the question of the real that different forms of theory have been attempting to define. But what philosophy often overlooks is the technological mediation of the real; the image of life is only made visible through certain technologies: conductors, filters, processes that make life "visible". Connecting Bergson with Foucault, we can articulate the matter of the biopolitical body whose fate is inevitably linked to its contemporaneous technology. The lcb's interactivities with technology provide a visible historicity of materialist biopolitics at work. The activation of technology is contingent upon the human body. But that 
contingency rests upon not just any body, but upon the specificities of participatory bodies. A Twitter informatic might direct the lcb to a certain territory, or might provide knowledge about a process of deterritorialization (becoming an a/political identity or becoming a surveillance lcb). Hooked up to a different piece of technology, such as a vibratory health machine, slicing machine, or computer terminal processing data, the material body processes the informatic feed of perceived and cognate sensory, electronic data to reconfigure its status in the world. Every interaction between the lcb and technology performs a biopolitical configuration of identity politics. Technology is not just prosthetic, it is always political in its accessibility and in its application by a specific lcb. Situation provides the analytic data of this body's historical issue and nature of participation (what, how, when), but does not answer the god-question of why? With Bergson, I call this body a technology-image among other images. As Foucault (2008) identified, technologies of security control the territorial movement and produce technology-images. These images are locked down into performing their determined fate within collective locations, with and through the actions of other images. This body is no "privileged" body, rather it is just a platform augmenting technology. In action, the technology-image facilitates what individuals call "human experience", but contributes to the formation of distinct groups of bio-politicized human bodies. This state of the mediatization of life is recorded and narrativized by other images. Questions concerning technology-images involve the predication of social differentiation categories that act as gatekeepers (such as "gender", "race”, "DNA", “sex", "age”, “culture”), the measurement of change, the implementation of new languages and laws. Analysis of the situation of technology-images is freely available for participants, yet the image controllers continue 
to insist on spatialized hierarchies to differentiate and enslave. As Haraway noted, in Western imagery and narratives, the notion of reality "is an effect but cannot be recognized as such without great moral and epistemological angst” (Haraway 1997, 182). The public effects of the harvesting of biopolitical data since Haraway wrote this at the end of the 1990s have dramatically changed. Territorial security patrols the biodata of the lcb. The image-reality of this mediatization has altered not only the reality-image of screen-formulated notions of the lcb, but all of the epistemological platforms from which the lcb operates. The scale of change of the concept of possible anthropos perspectival knowledge has both increased and diminished.

10. The biopolitic of the lcb may be harnessed, and the trajectory of its capital overlord remains schizoid. Some of the current problems facing the human race are their effects on the climate of the earth, causing rapid change. The results of this change are multiple and complex, one of them being the increase in the policing of the use and distribution of available resources, in turn escalating activities of militarism over the fight for resources. This unstable field of capitalist activity has resulted in uneven migratory patterns of humans, and escalated a change in the ways in which the matter of the world is configured. In this field, the bios; the life of any given lcb is always already given as a political measure of a particular time, and for a particular purpose. Given its variables, we ask then, to what extent does the imaged mediation of the bios contribute to a perspective of the life of the human body as a materially specific lcb? As a measure, the biopolitical image provides a filter for the political stasis of materials; the form of the lcb is charted by its modes and quantity of work, migratory patterns, reproductive statistics, health cost 
in its chronological life-time. This biopolitical duration of the lcb is contingent upon the technology of measurement used to moniter the lcb, and the territorially configured identity politics of the lcb. Combined, subject to schizoid and chaotic trajectories, these digital biopolitical measures provide the image of life as contingent, limited, and expendable. Describing the lcb as a biocoded body expresses the processes of information exchange at work in its manifested digital image. These processes are the data systems that perform as the platform, the filter, and the catalyst of energy materialized into codes, codes that are written according to perceptual schemas, points of view, laws and ideas. In writing these codes, exchange values often precede the systems of measurement that will be set up, determining what kinds of energies are to be measured as image functions: inequalities, surplus, desires, affects, fetishes, utility. In addition to measurement of the lcb, is the matter of the image itself. And what the lcb denotes to itself, is a measured experience, that has a finite singular duration, but one that is briefly connected within the larger biopolitical field of its sphere. Activated in politically determined ways, the matter of the lcb is gendered, racialized, aged, and durationally classifiable. Consideration of the materiality of the lived image of the lcb enables expressivity for the details of the field, and the potential for complete capture, or some relief through non-participation in the consumptive practices of capital. This enabling of the details of micro material experiences that capital, or even other lcbs, do not value or understand is the temporality of the lived body (see Fisher 2011), the image of which remains knowable for only the briefest of moments, and thus far remains uncoded. 
Notes

1 "Safe conduct" is given through the current UK identity card, containing bio-data information in the forms of ten encoded fingerprints and two eye scans, housed in small electronic chip. Nationality is emblazoned on the card, alongside a passport-style photograph, information about the date and location of birth, and a reduced-scale signature, alongside the various government symbols and insignia, including the symbol of the Europa white bull, representing Zeus, on the residence permit cards of all European Union countries this decade. The UK Royal insignia of a lion with a crown and a unicorn hugging a crowned medal reads honi soit qui mal y pense (Evil unto him who thinks evil of it), a phrase commonly used in insignia of British and Commonwealth military orders, and with the Latin inscription dieu et mon droit (God and my right). The four national flowers or plants of the countries that make up the United Kingdom are etched into the plastic - the rose, thistle, daffodil and shamrock. The whole is watermarked, sealed, and laminated. The symbols provide political perspective and remind the user of territorial boundaries. Genetic data is not required for the UK (in 2014). Ideological data asked for on the application form, which may or may not be embedded in the card, includes religion, sexual preference, marital status, and National Insurance number. Soon the national database of the UK NHS (National Health Service) will enable third parties (such as the UK Border Agency, potentially) access to the Western Health medical records associated with the name on the card. With healthcare and media predicted to be the two growth areas for the economies of the future, the connections between the two remain to be critically observed.

${ }^{2}$ For example, see Time magazine's 1993 “The New Face of America” 'Eve”,, reproduced in Hammonds 1997, 116. 